\title{
Regenerative nanomedicine: current perspectives and future directions
}

\author{
This article was published in the following Dove Press journal: \\ International Journal of Nanomedicine \\ I September 2014 \\ Number of times this article has been viewed
}

\author{
Koel Chaudhury \\ Vishu Kumar \\ Jayaprakash Kandasamy \\ Sourav RoyChoudhury \\ School of Medical Science \\ and Technology, Indian Institute \\ of Technology, Kharagpur, \\ West Bengal, India
}

\begin{abstract}
Nanotechnology has considerably accelerated the growth of regenerative medicine in recent years. Application of nanotechnology in regenerative medicine has revolutionized the designing of grafts and scaffolds which has resulted in new grafts/scaffold systems having significantly enhanced cellular and tissue regenerative properties. Since the cell-cell and cellmatrix interaction in biological systems takes place at the nanoscale level, the application of nanotechnology gives an edge in modifying the cellular function and/or matrix function in a more desired way to mimic the native tissue/organ. In this review, we focus on the nanotechnologybased recent advances and trends in regenerative medicine and discussed under individual organ systems including bone, cartilage, nerve, skin, teeth, myocardium, liver and eye. Recent studies that are related to the design of various types of nanostructured scaffolds and incorporation of nanomaterials into the matrices are reported. We have also documented reports where these materials and matrices have been compared for their better biocompatibility and efficacy in supporting the damaged tissue. In addition to the recent developments, future directions and possible challenges in translating the findings from bench to bedside are outlined.
\end{abstract}

Keywords: regenerative medicine, nanomedicine, nanotechnology

\section{Introduction}

An increasing gap between organ donation and organ transplantation has inspired scientists to find out alternative approaches and substitutes to make the organs functional. The US National Institutes of Health has defined regenerative medicine as "the process of creating living, functional tissues to repair or replace tissue or organ function lost due to age, disease, damage, or congenital defects." "1

With the advent of nanotechnology, regenerative medicine has evolved tremendously in recent years and appears to be a promising approach in restoring function and regeneration of diseased tissues and organs. Since cell function occurs at the nanometer scale, nanotechnology can influence and even alter cellular behavior, which ultimately enhances the functioning of tissue or organ. The traditional approaches of nanotechnology in regenerative medicine can be related to: 1) nanoparticles; 2) scaffolds with nanofibers; 3 ) scaffolds with nanotopographic modifications; 4) drug/ gene delivery; and 5) extracellular matrix (ECM) patterning. The newer and rational approaches include a combination of these traditional methods.

The purview of this article is to cover recent advances in nanotechnology for regenerative medicine. Only those organ systems have been considered where considerable research is ongoing. The information provided herein is mainly taken from the PubMed articles published over the last 6 years (2009-2014). The keywords specifically used to generate the literature search for this review paper were: "bone;" "cartilage;" "nerve;" "myocardium;" "skin;" "eye;" "teeth;" "liver;" "regenerative medicine;"
School of Medical Science and Technology, Indian Institute of Technology, Kharagpur, West Bengal, PIN 721302, India

$\mathrm{Tel}+913222283572$

Fax +91 3222282221

Email koel@smst.iitkgp.ernet.in submit your manuscript | www.dovepress.com

Dovepress

http://dx.doi.org/10.2147/IJN.S45332
International Journal of Nanomedicine 2014:9 4I53-4I67

4153

(c) (i) (5) 2014 Chaudhury et al. This work is published by Dove Medical Press Limited, and licensed under Creative Commons Attribution - Non Commercial (unported, v3.0) License. The full terms of the License are available at http://creativecommons.org/licenses/by-nc/3.0/. Non-commercial uses of the work are permitted without any further perm sion how to request permission may be found at: http://www.dovepress.com/permissions.php 
and "nanotechnology." Most of the references in this review paper are the original research articles; a few refer to recent reviews on the topic. This review article discusses various advances in nanotechnology-based regenerative medicine for the repair or enhancement of damaged tissues function in various organ systems. Table 1 summarizes the different nanomaterials recently used for tissue/organ regeneration with the references. Figures representing the nanotechnologybased approaches for regeneration of bone (Figure 1) and skin (Figure 2) are included.

\section{Bone tissue regeneration}

Bone tissue may be considered as a nanocomposite consisting mostly of collagen and hydroxyapatite (HA) containing calcium phosphate. Embedded in this matrix are osteocytes, osteoblasts, osteoclasts, and other smaller bone-related proteins. Bone tissue loss may occur due to trauma, organic bone diseases, infectious diseases, and surgeries; reconstruction of the functional bone remains a major challenge for the orthopedic surgeons.

Fractured bone regeneration is a very slow and incomplete process. Earlier, autografts and allografts were used to induce bone regeneration, with both the grafts showing equal regenerative potential. ${ }^{2}$ However, the use of these grafts is limited owing to inadequate availability, risk of infections (allograft), donor site morbidity, blood loss, and harvesting complexity. The ideal bone graft should be pathogen-free, osteoinductive, biomechanically stable, and have minimal antigenicity. ${ }^{3}$

Bioinert materials have also generated considerable interest for providing mechanical support without causing significant immune responses. The practice is now changing toward the use of bioactive materials as implants for fractured bone regeneration. ${ }^{4,5}$ It is being increasingly accepted that the bioactive coating of implants creates improved implantbone integration. ${ }^{6}$ Advances in nanotechnology and tissue engineering have provided promising options to regenerate and to replace damaged bone. ${ }^{7}$

Recent advances in nanotechnology-based bone regeneration are discussed briefly under two sections - "Nanostructured scaffolds" and "Nanotechnology-based stem cell differentiation."

\section{Nanostructured scaffolds}

Various nanotechnology-based matrices have been developed over the past decade. The most commonly explored ones are: the carbon nanotubes (CNTs); electrospun HA; anodized titanium; and nanotitanium. ${ }^{8-12}$ Osteoblasts show better cell attachment, proliferation, and mineralization in nanofibrous scaffold. The fabrication of nanofibers into complex threedimensional structures is necessary. Nanofibers incorporated onto spiral poly(epsilon caprolactone) three-dimensional scaffolds, when seeded with osteoblasts, have shown better cell attachment, proliferation, differentiation, and mineralization as compared to cylindrical scaffolds. Based on these findings, spiral-structured nanofibrous scaffolds seem to be a promising alternative for bone tissue-engineering applications. ${ }^{13}$

Bioinspired structures, such as synthetic HA with pores, patterns and textures in nanoscale size, act as a morphological cue for bone cell regeneration. Nanoscaled calcium phosphate can be synthesized by sol-gel, precipitation, hydrothermal, and electrospinning processes. The products of these processes are calcium phosphate nanocomposites, nanostructured monophasic calcium phosphate bone fillers, nanostructured precursor phases for calcium phosphate cements, nanostructured calcium phosphate coatings, and nanostructured polyethylene. ${ }^{14-16}$ The in vitro studies on electrospun calcium phosphate seeded with osteoblasts and monocytes suggest good biocompatibility without any negative effects on cell proliferation. ${ }^{11}$ HA-coated titanium implants are reported to accelerate and to enhance osseoimplant integration in rat models. Nanopolymeric HA coated over microroughened titanium implants increases the surface area considerably, resulting in an increase in osteoconductivity and inhibition of local soft tissue infiltration. ${ }^{17}$ The in vivo studies have shown that the HA nanoparticles coated over titanium implants are nontoxic, as these nanoparticles are removed from the body through a natural waste-clearing mechanism. ${ }^{18}$ Further, the addition of metallic nanoparticles enhances the biological properties of routinely used chitosan, HA nanoparticles. The use of chitosan-nano-HA copper zinc alloy nanoparticles in bone tissue engineering has shown a considerable increase in protein adsorption and antibacterial properties. ${ }^{19}$

Nanostructured beta tricalcium phosphate ( $\mathrm{n}$ beta TCP) coatings on scaffolds are reported to enhance their biological properties. Increased osteoconductivity and improved mechanical properties are documented for $\mathrm{n}$ beta TCP-coated poly(lactic acid) (PLL) scaffold, which depends on the $\mathrm{n}$ beta TCP ratio. ${ }^{20}$ Several groups have observed that the incorporation of nano-HA into the gelatin increases the mineralization of the matrix and the alkaline phosphatase activity; this results in active bone growth in rat calvaria. ${ }^{21,22}$ Also, the antimicrobial agents mixed with the nanoparticulate components for bone regeneration are thought to be more useful than traditional treatment, especially in cases of long-standing osteomyelitis. ${ }^{23}$

Demineralized bone matrix is an osteoconductive material containing most of the proteinaceous bone components, 


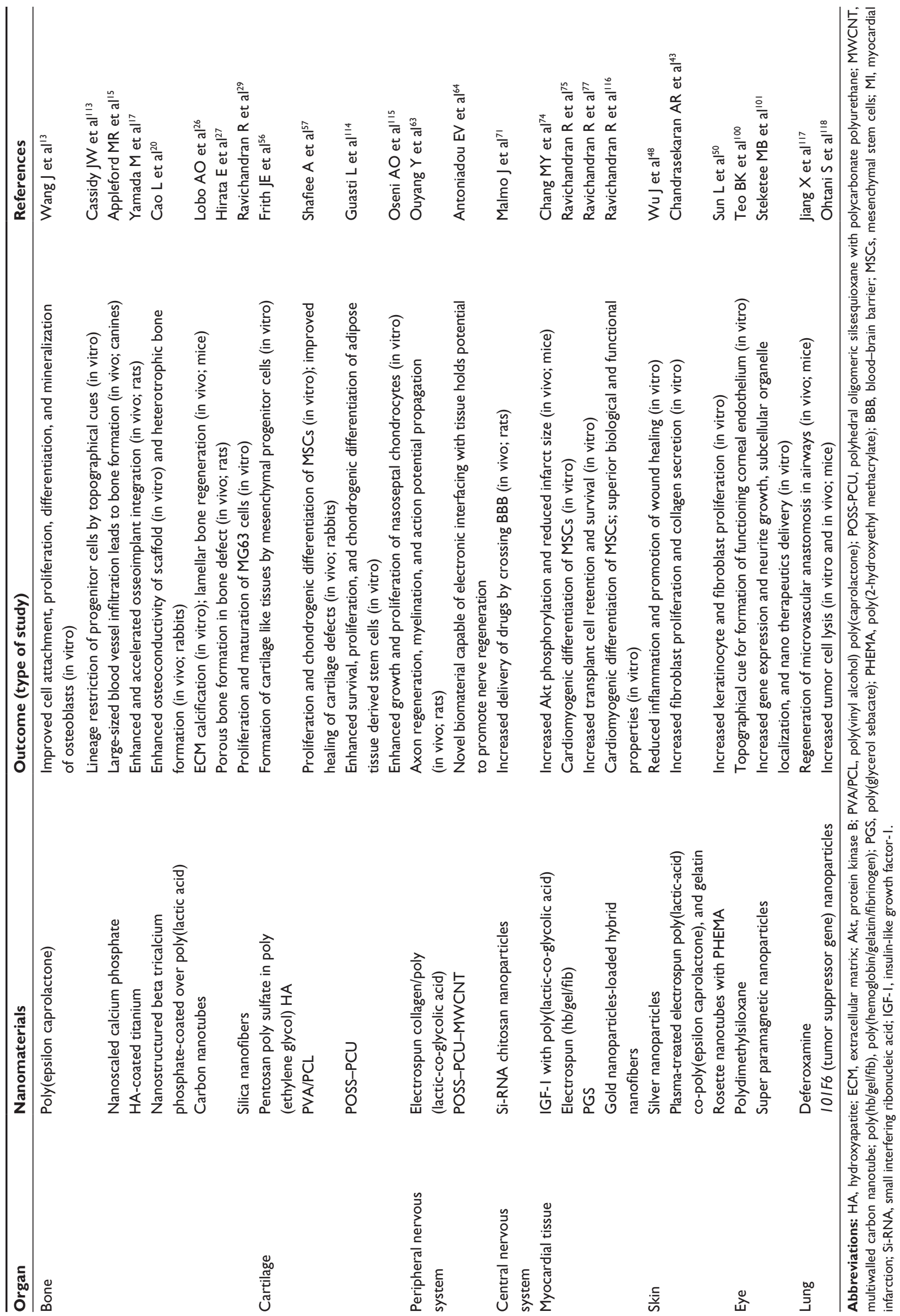




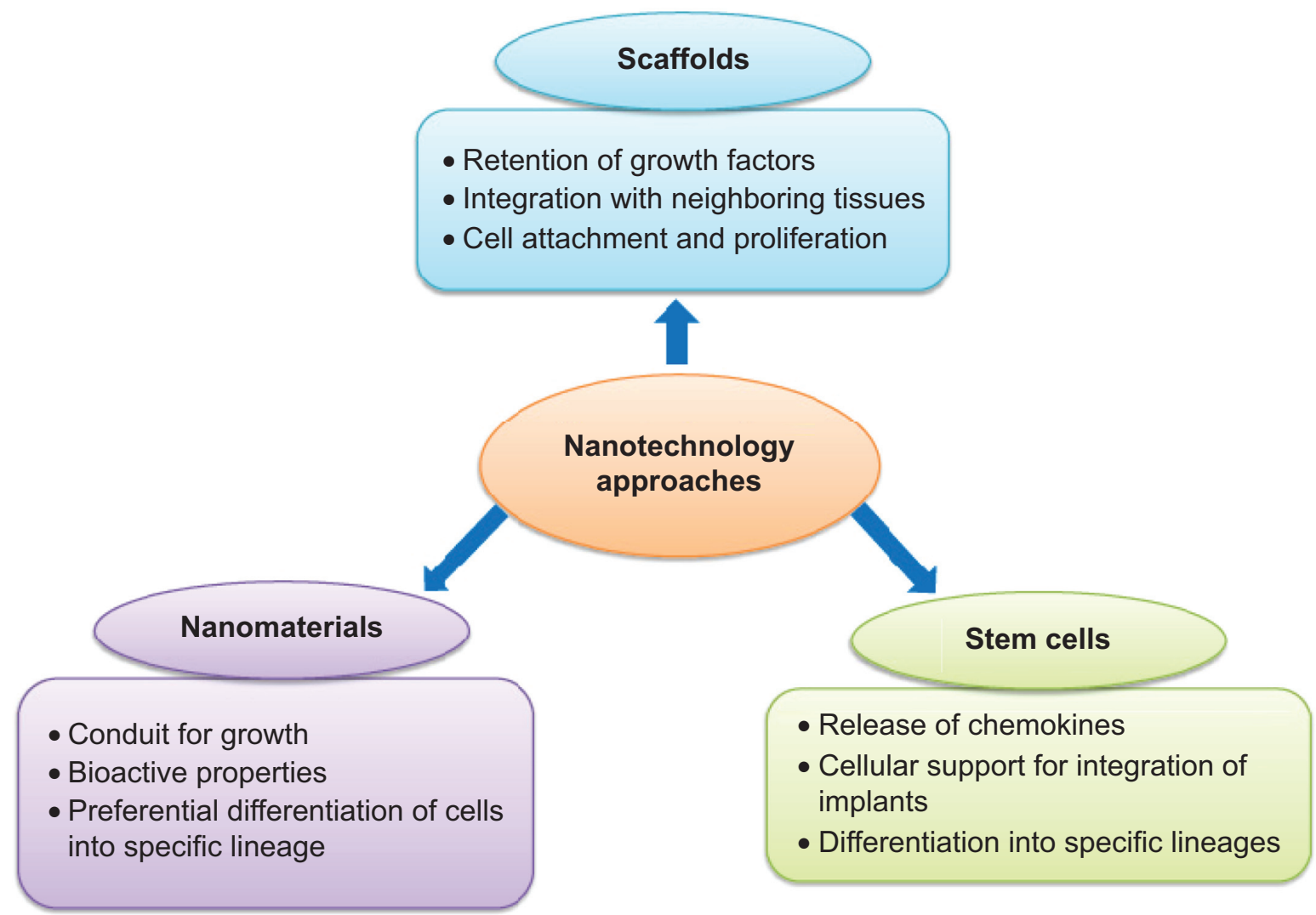

Figure I Various nanotechnology approaches in regenerative medicine.

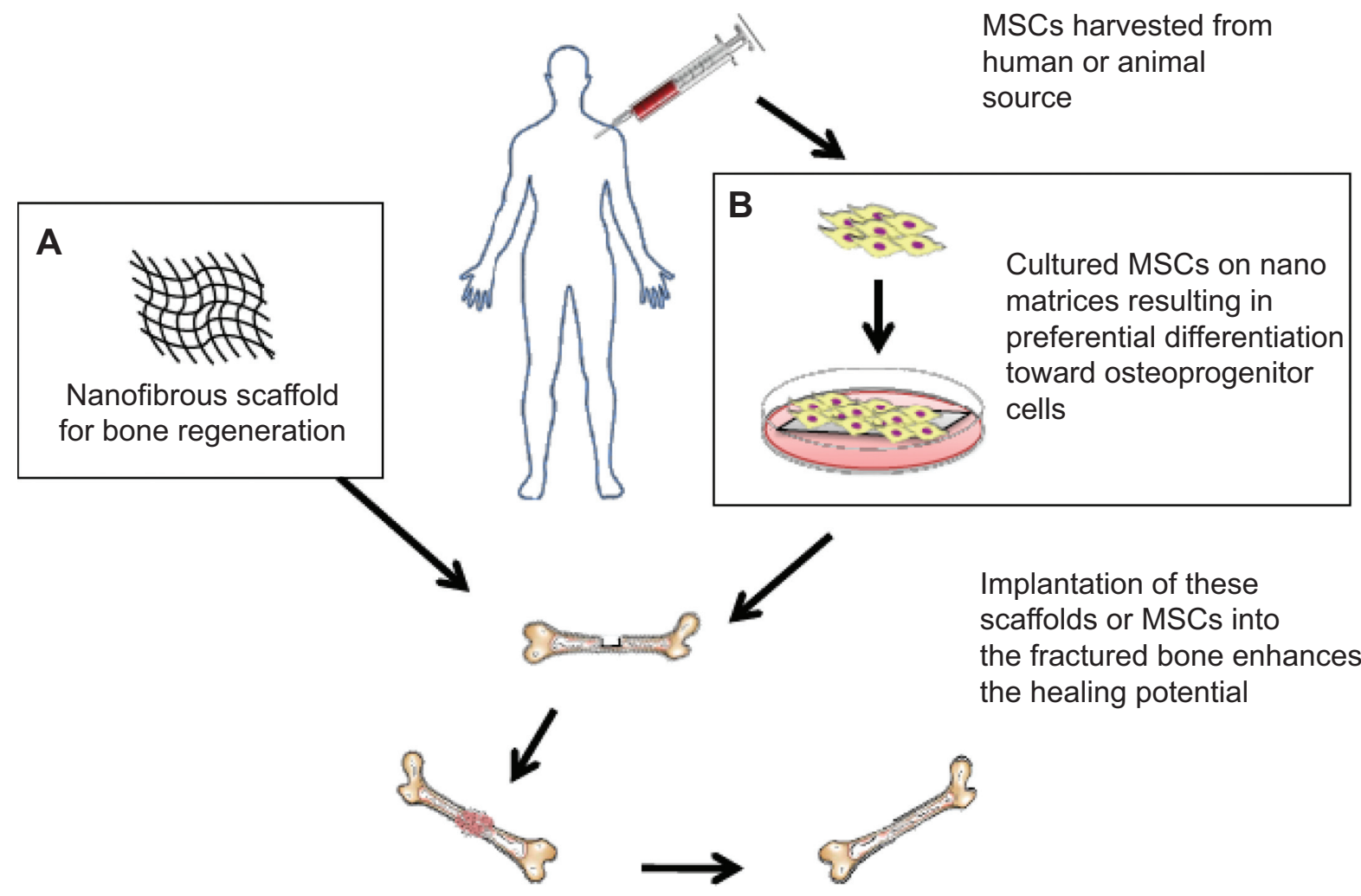

Figure 2 Schematic representation of bone regeneration using nanotechnology.

Notes: Improved bone healing using (A) nanofibrous scaffold and (B) culturing MSCs on nano matrices.

Abbreviation: MSCs, mesenchymal stem cells. 
which are potent osteogenic agents. ${ }^{24}$ Demineralized bone matrix is a good substitute for bone and is used as a bone grafting material, the efficacy of which depends on the carrier substance. An in vivo study that compared two of the most commonly used carriers, albumin and carboxymethyl cellulose, indicates that albumin is associated with strong regenerative properties. ${ }^{25}$

CNTs, both single-walled and multiwalled types, are reported to have good osteoinductive and accelerating cell proliferative properties solely, or in combination with, nano-HA. ${ }^{26}$ The fibroblast growth factor-incorporated CNTs have shown an increase in osteoblastic proliferation. ${ }^{27}$ The porous chitosan scaffold, with varying degrees of nano-HA composition, has been studied by incorporating a single-walled magnetically produced CNT (B-SWCNT) and nonmagnetically produced H-SWCNT, where B-SWCNT was found to have superior biocompatibility properties. ${ }^{28}$

Mesoporous materials have pore size between 2-50 nm. Ravichandran et al have reported that mesoporous silica nanofibers have improved bioactivity. Osteoblast-like cells (MG63) have good growth and proliferation potential with the upregulation of collagen I and alkaline phosphatase. ${ }^{29}$

\section{Nanotechnology-based stem cell differentiation}

In addition to the synthetic nanoparticulate matrix modification, the concept of using stem cells for bone regeneration is increasingly gaining popularity, owing to their better proliferation properties and ability to differentiate into many cell lineages. ${ }^{30}$ Mesenchymal stem cells (MSCs) are most commonly used for bone tissue regeneration. Nanoscale modification of the matrix further enhances their growth and differentiation. Bone marrow-derived human MSCs (hMSCs) can be stimulated to differentiate into chondrogenic and osteogenic lineages by a group of nanoscale biomaterials, like porous silk fibroin/chitosan, PLL/nano-HA, and electrospun HA/chitosan. ${ }^{8,31-34}$

A recent study comparing the effects of nanomaterials and bone specific growth factors has shown that nanomaterials are equally effective in inducing bone growth. Poly lactic acid/nano-HA seeded with human MSCs have osteogenic potential comparable to that of direct injection of bone morphogenic protein $7 .{ }^{35} \mathrm{CNTs}$, as mentioned earlier, can also be used as a substrate for seeding and enhancing growth and differentiation of hMSCs toward osteoblast-like cell lineages. These hMSCs are able to recognize the alignment of CNTs, with better growth potential observed for aligned CNTs than the nonaligned ones. ${ }^{36}$
Surface modification of nanostructures is a well-known approach for modification of their biological activity. On comparing plain $\mathrm{TiO}_{2}$ nanotubes with carbon-coated $\mathrm{TiO}_{2}$, the latter was seen to have better osteogenic differentiation potential. ${ }^{37}$ Nevertheless, toxicity due to surface modification remains a matter of concern. Carboxylated CNTs have shown cytotoxic effect and were also found to inhibit MSCs differentiation, which is possibly modulated by a SMADdependent bone morphogenic protein signaling pathway. ${ }^{38}$

Human embryonic stem cells can be programmed to develop into bone-forming cells with a better osteocalcin messenger ribonucleic acid expression on the nanofibrous scaffold than the solid walled ones. ${ }^{39}$

\section{Skin regeneration}

The skin is the largest organ in the body that provides mechanical support to inner organs, regulates body temperature, and plays a critical role in the synthesis of vitamin D. It is more prone to mechanical injuries and infection because it is the outermost covering of the body. Presently, no bioengineered skin models exist that can completely mimic the anatomical, physiological, and biological characteristics of normal, healthy skin. ${ }^{40,41}$ It is important to mention that wound healing using nanotechnology remains a major area of research interest worldwide and an exhaustive report on this topic is beyond the scope of this review. Nevertheless, the research efforts concerned with skin regeneration are briefly outlined in the following sub-sections: (i) nanostructured scaffolds (ii) nanoparticles as delivery systems (iii) hydrogels and (iv) stem cells for skin regeneration. A schematic representation of skin regeneration by nanotechnological approaches is shown in Figure 3.

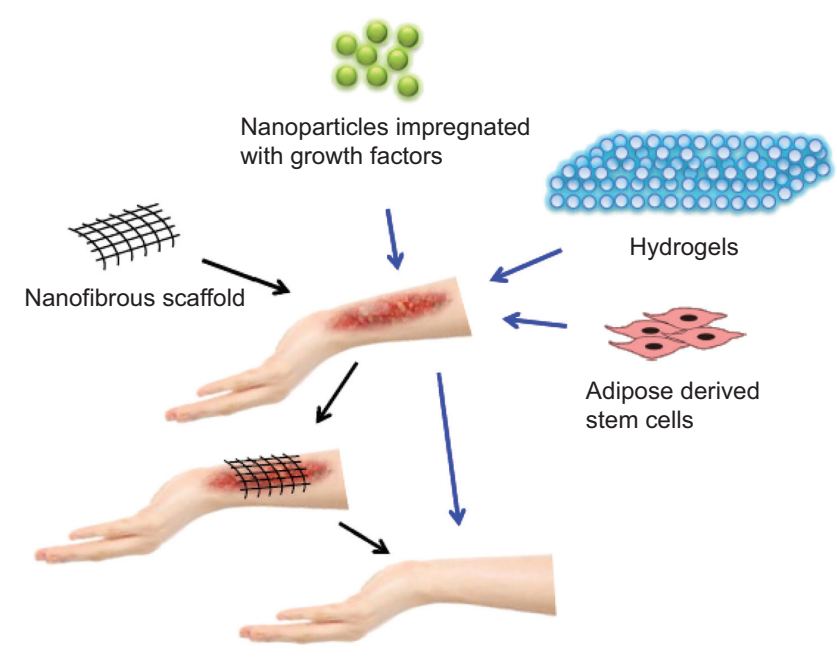

Figure 3 Various nanotechnology-based methods for skin regeneration. 


\section{Nanostructured scaffolds}

Protein fibers, like collagen, fibronectin, laminin, and keratin, in the dermis of skin are in the scale of $30-130 \mathrm{~nm}$. These structures are responsible for cell proliferation and migration. ${ }^{42}$ Several approaches are available for the fabrication of synthetic ECM in nanoscale to mimic the natural environment. Development of skin substitutes with electrospun nanofibers has recently received substantial importance for skin tissue regeneration. Electrospun nanofibers have shown uniform attachment to the surface of the wound without causing an accumulation of fluid. Plasma-treated electrospun poly(L-lactic acid) (PLLA)co-poly( $\varepsilon$-caprolactone) gelatin-based scaffold has shown increased wound healing properties by significantly accelerating cell proliferation and cell adhesion. ${ }^{43}$ This is attributed to the numerous integrin-binding sites present in gelatin that help in cell adhesion. The incorporation of multiple wound healing mediators in biodegradable scaffolds holds promise for the development of controlled drug delivery systems for skin tissue regeneration. A recent study reports encapsulation of multiple epidermal induction factors (EIF) in core-shell nanofibers where the concomitant release of multiple growth factors from the scaffold showed increased cell proliferation. ${ }^{44}$

\section{Nanoparticles-based skin regeneration}

Skin regeneration involves attraction of cells and their migration, proliferation of keratinocytes/fibroblasts, and angiogenesis to accelerate these processes. ${ }^{45}$ Platelet-derived growth factor, epidermal growth factor, fibroblast growth factor, insulin-like growth factor (IGF), transforming growth factor-beta, and vascular endothelial growth factor (VEGF) are some of the typical growth factors involved in this process. Nanotechnology helps in delivering these growth factors effectively at the target site and also extends local availability considerably, thereby reducing the healing time. Most of the growth factors used in skin regeneration are administered topically using gelatin, collagen, and hyaluronic acid-modified systems. ${ }^{46}$ Keratinocyte growth factor 2 (KGF 2) - also known as fibroblast growth factor 10 - can be administered topically as well as in an injection form. It has shown significant wound-healing properties. As compared to free KGF 2, the controlled and prolonged release of KGF 2 is reported in dextran sulfate-bound KGF 2 complexed with several polycations (chitosan, poly-Llysine, and polyethylenimine). This resulted in a significant increase in the mitotic rate of human umbilical cord vascular endothelial cells. ${ }^{47}$
Silver nanoparticles are clinically used either as individual topical application or impregnated in scaffolds. Their antimicrobial and anti-inflammatory properties help in accelerating wound repair. A recent study has shown that silver nanoparticles, when impregnated on bacterial cellulose nanofibers, increase efficacy and reduce toxicity considerably. ${ }^{48}$ The bioactivation of scaffold is an alternative approach for skin tissue regeneration. A recent report suggests that the activation of the collagen scaffold with the copolymer-protected gene vectors (COPROGs) induces the temporary release of VEGF, an important factor for angiogenesis. On placing the collagen scaffold with COPROGs on the wound bed, the infiltrated cells on the scaffold became transfected with COPROGs and started to synthesize and to release VEGF. ${ }^{49}$

\section{Hydrogels}

Hydrogels have been widely investigated for use in regenerative medicine; however, nanohydrogels remain less explored. Rosette nanotubes (RNTs) are nanomaterials that have structures similar to natural skin nanostructures, like collagen and keratin. With their self-assembling and solidification properties when transitioning from room to body temperatures, RNTs may be the next-generation skin wound healing materials. The RNTs incorporated into poly (2-hydroxyethyl methacrylate) (PHEMA), commonly used hydrogels for skin regeneration, are reported to increase keratinocyte and fibroblast proliferation, highlighting the proactive property of RNTs. ${ }^{50}$

The homogeneous distribution of nanofibrin composite in chitosan hydrogel is considered to be a biodegradable, nontoxic matrix for skin tissue regeneration. In vivo studies on Sprague-Dawley rats using this hydrogel have shown faster wound healing response evidenced by increased collagen deposition. ${ }^{51}$ Hydrogels are also effective in the controlled release of impregnated drugs, which is essential for the sustained stimulation of tissue growth. An interesting study by Jaiswal et al has shown that poly(vinyl alcohol) hydrogel impregnated with epigallocatechin gallate is very effective in healing wounds by improving angiogenesis, restoring epithelialization, and decreasing the inflammatory response. $^{52}$

\section{Stem cell-based skin regeneration}

Stem cell-based therapy seems to be a promising option for skin regeneration. This therapy makes use of various types of cells, such as circulating endothelial cells, MSCs, bone marrow-derived stem cells, adipose-derived stem cells 
(ASCs), etc. Among these, the ASCs have received maximum attention and are, therefore, most clinically tested. This is because of their abundant availability, easy harvesting, and better healing properties, due to the secretion of growth factors. It is, however, important to remember that stem cell-based therapy can be utilized to the maximum only if suitable scaffolds are developed that can efficiently differentiate these stem cells into dermal tissue. The development of an ideal scaffold for cell-based regeneration is far from complete and still remains a challenge. Ravichandran et $\mathrm{al}^{53}$ have explored the use of electropsun poly-L-lactic acid/ poly- $(\alpha, \beta)$-DL-aspartic acid/collagen nanofibrous scaffold as a substrate for the differentiation of ASCs. ${ }^{53}$ The scaffold showed better proliferative and differentiation properties as compared with scaffolds without collagen. The authors propose that the scaffold, along with the ASCs, can heal damaged skin tissue by means of paracrine signaling. ${ }^{53}$

The mechanical and physicochemical properties of the scaffold can alter the fate of the cells seeded on it. The difference in manufacturing technique imparts varied characteristics to the scaffold. Jin et $\mathrm{al}^{44}$ have compared EIF encapsulated core-shell nanofibers of gelatin and poly (L-lactic acid)-co-poly-( $\varepsilon$-caprolactone) (PLLCL) prepared by coaxial electrospinning with EIF-blended nanofibers prepared by electrospinning a blend solution of EIF with gelatin and PLLCL. Core shell nanofibers seemed to be a better substrate for epidermal differentiation of adipose-derived stem cells and also exhibited improved biocompatibility as compared to blended nanofibers. Further, the release of the EIF was also regular, slow, and long-lasting in core-shell nanofibers. ${ }^{44}$

\section{Cartilage regeneration}

Cartilage, composed mostly of type II collagen, is the nonmineral component of the skeletal system and provides frictionless joint mobility. The natural healing mechanism of cartilage injury is limited, due to its avascularity and absence of stem cells. Recent nanotechnology advances have the potential to be translated into the clinical applications by increasing the healing ability of the cartilage significantly.

Electrospun nanofibers, when incorporated into the microfibrous scaffold, make the scaffold mimic native ECM, thereby maintaining cellularity under serum-free conditions. This enhances the deposition of glycosaminoglycan (GAG) on the scaffold, which is proven to be an effective method for cartilage regeneration. ${ }^{54}$ The generation of scaffolds similar to in vivo conditions by the incorporation of proteins and the GAG in peptide nanofibers resulted in the accumulation of GAG and the formation of cartilage tissue nodules in the seeded chondrocytes. Both chemical and structural mimicry of ECM are needed for this purpose, which can be achieved by adding functional groups to self-assembled peptide nanofibers. ${ }^{55}$ Pentosan polysulfate (PPS) is a highly sulfated semisynthetic polysaccharide that has the potential to differentiate mesenchymal progenitor cells into chondrocytes when added to the culture medium. PPS, when added to polyethylene glycol (PEG)-HA medium, both in soluble and bound form, is reported to increase chondrocyte differentiation of hMSCs, with the bound form having more efficacy than the soluble form. These findings make PPS in PEG-HA a promising option for use in intervertebral disk regeneration. ${ }^{56}$

Shafiee et $\mathrm{al}^{57}$ have compared stem cells-coated poly vinyl alcohol/poly PCL scaffold with uncoated ones for cartilage regeneration and found the former scaffolds to have more efficient cell growth and differentiation properties. They conducted both in vitro and in vivo studies using rabbit bone marrow MSCs. The in vitro experiment highlighted the chondrogenic differentiation potential of the scaffold. The in vivo study performed on the cartilage defects indicated that the MSCs-coated scaffold has better healing properties when compared to uncoated scaffolds. ${ }^{57}$ The utilization of functional biomimetic scaffolds for the regulation of stem cell differentiation is emerging as a significant area of tissue engineering. Holmes et $\mathrm{al}^{8}$ have shown that the scaffolds made of PLLA in serial dimensions have better hMSCs proliferative properties for smaller diameter fibers. They found that these PLLA scaffolds, when coated with hydrogen-treated multiwalled carbon nanotubes (MWCNT), have mechanical properties similar to that of natural cartilage. The same group has shown that the modification of the PLLA scaffolds by coating with poly-lysine and adding hydrogen-treated MWCNT increase the chondrocytic differentiation of hMSCs significantly. On culturing hMSCs on these modified scaffolds, a significant amount of GAG synthesis was observed. ${ }^{8}$

\section{Nerve regeneration}

Nerve tissues are comprised of neurofibrils enclosed inside the nerve sheath. It becomes difficult for the nerve to regenerate and attain its functional ability when the neurofibrils are damaged along with the loss of nerve sheath continuity. In such cases, the surgeon uses a graft or a guiding material for the nerve to reach its distal end and attain functionality. ${ }^{58}$

An excellent review by Biazar et al discusses various types of biologic nerve conduits and synthetic nerve guides. ${ }^{59}$ Cirillo et a ${ }^{60}$ have done extensive research on the 
development of aligned electrospun nanofibers for nerve regeneration. They prepared an electrospun PCL membrane, enhanced it with gelatin, and studied its biological response following treatment with the PC-12 pheochromocytoma nerve cells. The group successfully demonstrated that fully aligned PCL nanofibers with gelatin macromolecules provide adequate contact guidance to the nerve cells as compared with randomly aligned fibers. These fully aligned nanofibers act as a topological cue for neurite growth, thereby improving nerve regeneration. ${ }^{60}$

The in vivo studies of intraluminal nanofibrous nerve guides for nerve injury repair have shown considerable improvement in nerve growth potential. The conduits are coated with laminin and nerve growth factors for this purpose. Longitudinal alignment of the fibers within the conduit also plays a role in regeneration. ${ }^{61}$ The in vivo studies performed in the sciatic nerve-defect rat model suggest that the nanoporous scaffolds have better nerve regeneration potential compared with microporous scaffolds. The nanoporous scaffolds were found to stimulate longitudinally directed nerve fiber growth along the pores while the growth was toward the wall in the case of the microporous scaffolds. ${ }^{62}$

Although the autologous nerve grafts are considered to be superior to the synthetic nerve conduits, availability is a limiting factor. Nerves guided by the highly longitudinal aligned electrospun collagen/poly(lactic-co-glycolic acid) (PLGA) nerve conduits have shown superior action potential conduction and morphology compared with those guided by randomly arranged fibers. ${ }^{63}$ The MWCNT combined polyhedral oligomeric silsesquioxane and polycarbonate polyurethane (POSS-PCU/MWCNT) and also MWCNT combined PCL urea (POSS-PCL/MWCNT) are two conductive nanopolymers extensively researched for nerve regeneration purposes. ${ }^{64}$ Studies performed on the in vitro rat spinal cord cells coated over carbon nanotubes have shown the proliferation and expression of functional maturation markers - that is, development of action potential and generation of voltage dependent current. Further, the microarray studies suggested the presence of the active repair process involving microglia in the absence of reactive gliosis. ${ }^{65}$

Nanotechnology approaches can also be used to regenerate chronically injured nerve cells. An interesting study has shown that the incorporation of electrospun nanofibers, self-assembling peptides, and proregenerative cytokines into guidance channels of the chronic spinal cord injured rat model resulted in a well-developed vascular network, basal lamina, and myelin, which eventually leads to enhanced electrophysiological recovery. ${ }^{66}$ Another study that compared double-layered aligned and random nanofibers in vitro for the growth of the dorsal root ganglia reports that the random nanofibers impair the growth of dorsal root ganglia, which can be effectively reverted by the seeding of Schwann cells over the random nanofibers. An in vivo study of the same doubled-layered nanofibers showed comparable efficacy to that of isograft in terms of morphological and electrophysiological properties. These nanofibers were fabricated by electrospinning of the PCL. ${ }^{67}$ The functionalization of the nanostructured scaffolds by peptides improves the activity of Schwann cells, thereby resulting in nerve regeneration. This is demonstrated by Masaeli et al ${ }^{68}$ who coated electrospun scaffolds of poly(hydroxyl butyrate) and poly(3-hydroxybutyrate-co-3-hydroxyvalerate) with collagen and then cultured Schwann cells on these scaffolds. They observed a preferential unidirectional growth and better neurotrophin expression as compared to untreated scaffolds. ${ }^{68}$

One important aspect of the central nervous system (CNS) regeneration is to ensure that the drugs for degenerative diseases cross the blood-brain barrier (BBB) and reach the brain. Along with tight junctions, the adenosine 5 '-triphosphate (ATP) binding cassette reduces the entry of drugs into the brain cells. Nanoparticles reach the brain parenchyma evading these mechanisms, thus making them favorable for neuronal drug delivery. ${ }^{69}$ Surface-modified chitosan nanogels loaded with methotrexate injected in animals have shown higher concentration of nanogelincorporated drug in the brain compared with the raw drug, but no difference in concentration due to surface modification. This indicates that nanogels can be utilized for drug delivery into the CNS, due to their efficiency in crossing the BBB effectively. ${ }^{70}$

Another hurdle for drug delivery into the CNS is the efflux pumps that actively transport the drug outside the cells. The P-glycoprotein (P-gp), having several substrates, is one of the efflux pumps for the drugs delivered into the brain cells. Small interfering ribonucleic acid chitosan nanoparticles have been used for P-gp silencing, which decreases the P-gpdependent efflux and, hence, increases drug concentration in the brain. ${ }^{71}$

The distinctive regeneration characteristics between the CNS and peripheral nervous system (PNS) limit the application of nanobiotechnology in the CNS regeneration as compared to the PNS. This is due to the active role of the myelin sheath and the Schwann cells in PNS regeneration, in contrast to the limited success of oligodendrocytes remyelinating the nerve cells in the CNS. 


\section{Myocardial regeneration}

Cardiac myocytes are cells with restricted growth, which following an ischemic injury - may preferentially undergo scarring due to their limited regenerating capability. The dreaded complication of myocardial infarction is the cardiac rupture, which is a sequel to cardiac scarring. This can be prevented if the death of the cardiac myocytes is checked, and the regeneration of myocytes augmented. ${ }^{72,73}$ The insulin-like growth factor 1 (IGF-1) complexed with PLGA nanoparticles, when injected into the ischemic myocardium, has shown a significant decrease in myocardial apoptosis by inducing (protein kinase B) Akt phosphorylation. With a decrease in the size of the PLGA, the amount of IGF-1 complexed in it increases considerably and, hence, enhanced Akt phosphorylation activity. ${ }^{74}$

It is suggested that the pretreatment of hMSCs with scaffolds having high oxygen-carrying capacity may result in the preferential cardiomyogenic differentiation, ex vivo. The high oxygen-carrying capacity of electrospun hemoglobin/ gelatin/fibrinogen nanofibers has been used to treat MSCs, which has led to their enhanced differentiation into cardiomyocytes. These nanofibers, cross-linked with phytic acid, hold promise to be an effective therapeutic agent for myocardial regeneration. ${ }^{75}$ Biomaterials made of poly(glycerol sebacate) (PGS) core polymer and gelatin shell polymers have good cell adhesion, proliferation, and cytocompatibility properties. ${ }^{76}$ Ravichandran et al have observed that the transplantation of the cells - along with the short nanofibers of PGS into the infarcted myocardium - results in an enhanced retention of the cells and increased expression of cardiac proteins like troponin, actinin, and connexin 43 , compared with the standard cell injection system. ${ }^{77}$

\section{Dental regeneration}

The human tooth consists of two major parts, the visible crown and the root; the root is usually not visible and is anchored within the bone. Enamel, dentin, pulp, and cementum are the four different tissues present within each tooth. Dentin, which makes up the majority of the inner surface of the tooth, mainly contains collagen I fibrils. Diseases affecting the teeth are increasingly encountered nowadays, mainly due to changes in food habits and an increase in the longevity of humans, making them edentulous. Carious infections of the teeth tend to decrease the degree of calcification that adversely affects the strength of the teeth. ${ }^{78}$ The potential application of nanotechnology in dentistry is the development of the long-lasting biocompatible dental implants with improved osseointegration and mechanical properties. ${ }^{79}$ These surface-modified

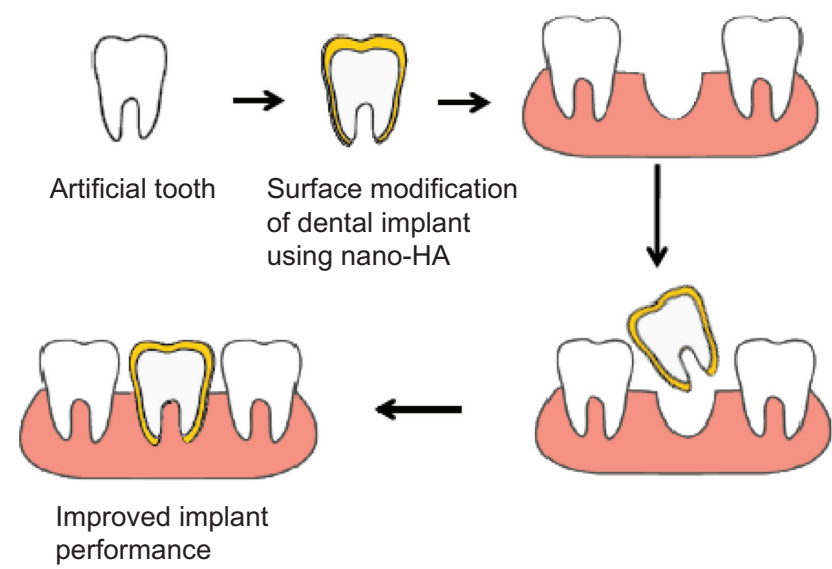

Figure 4 Surface modification showing improved performance and longevity of dental implants.

Abbreviation: HA, hydroxyapatite.

implants have the potential of effectively replacing, both structurally and functionally, the worn-out tooth and are being increasingly recognized as the most promising option for dental regeneration. A schematic diagram showing surface modification of dental implants for improved implant performance is depicted in Figure 4.

The usefulness of nano-HA has been successfully demonstrated for bone tissue engineering applications. In recent years, various research groups have shown substantial interest in using nano-HA for dental regeneration. Kasaj et a ${ }^{80}$ have explored the proliferation of periodontal ligament cells (PDL) cultured in the presence of nano-HA to understand its molecular mechanism of action. They found nano-HA paste to be a good stimulator of PDL cell proliferation mediated by the epidermal growth factor receptor, followed by the activation of extracellular signal-regulated kinases $1 / 2$ and Akt. ${ }^{80}$ The in vitro cell culture studies have shown that nano-HA stimulates the proliferation and differentiation of alveolar osteoblasts, resulting in alveolar bone regeneration. ${ }^{81}$ Similarly, it exerts a positive reinforcement in accelerating the proliferation potential of cultured human PDL cells, as evidenced by an increase in the ratio of cells in $\mathrm{S}$ phase to G1 phase after being cultured in nano-HA suspension. ${ }^{82} \mathrm{HA}$ nanoparticles - along with silica nanoparticles - increase the remineralization potential of dentin. This is evidenced by an increase in calcium and phosphorus content of dentin and an improvement in heterogeneous mineralization as seen in micro-computed tomography. ${ }^{83}$ Nano-HA-coated silk scaffolds improve the regeneration of both PDL cells and human dental pulp stem cells (hDPC) in dogs. This is due to an improved cell attachment and enhanced ECM formation promoted by the scaffold. ${ }^{84}$ 
In the arena of artificial denture, the nano-filled composite resin tooth is considered to have better mechanical properties and takes a longer time to wear out as compared to acrylic resin denture. The nano-filled composite resin tooth is the best-suited for both complete denture and partial denture development. ${ }^{85}$ Bioactive glass (BG) is being extensively explored to design novel dental materials; however, a literature search shows that well-explored reports on biologic effects of BG are lacking. ${ }^{86,87}$ Nanotechnology can be combined with the growth potential of stem cells for improving dental regeneration. ${ }^{88} \mathrm{~A}$ recent study on the effect of the nano $\mathrm{BG}$ on the proliferation of hDPC has shown an increased mineralization and expression of odontogenic-related protein in nano BG, compared with micro BG. This shows the efficiency of $\mathrm{hDPC}$ in odontogenic differentiation and dentin formation potential by nano $\mathrm{BG}$ induction. ${ }^{87}$

In vitro cell culture study performed on $\mathrm{hDPC}$ has shown that scaffold made of nanofibrous gelatin/silica BG has better odontogenic differentiation potential as compared to scaffolds without bioactive glass. ${ }^{89}$ In vitro culture studies in bovine enamel have established the antierosion properties of nano HA when mixed with sports drinks. ${ }^{90}$ Another in vitro study has proved the efficacy of nano carbonate apatite in preventing the restaining after the bleaching of the dental enamel. ${ }^{91}$ There are clear reports on the antibacterial effects of silver nanoparticles and silver-impregnated nano BG in the prevention of caries. ${ }^{92,93}$

\section{Hepatic regeneration}

Nanotechnology application for hepatocyte regeneration is a relatively new but rapidly developing field with a promising future. Nanoparticles and nanostructured scaffolds provide an exact mimic of hepatic ECM facilitating the differentiation of progenitor cells into hepatocytes. The challenge in hepatic regeneration is the ex vivo maintenance of the harvested hepatocytes in a medium similar to in vivo characteristics. Giri et $\mathrm{al}^{94}$ have used self-assembling peptides with a special combination of growth factors to mimic an in vivo hepatic microenvironment. This nanomaterial was able to maintain the hepatocytes for 3 months with functional efficacy and without causing any toxicity. ${ }^{94} \mathrm{~A}$ recent achievement in the hepatic regeneration is the development of silymarin nanoparticles using nano precipitation. These silymarin nanoparticles are hepatoprotective and have been found to be useful in preventing paracetamol-induced liver damage by increasing the hepatic glutathione level. ${ }^{95}$

It is well-known that the MSCs derived from bone marrow, adipose tissue, and myeloid differentiate into hepatocyte-like cells. ${ }^{96,97}$ An in vivo study using chitosan-alginate polyelectrolyte complex fibrous nonwoven scaffold seeded with hMSCs into rat liver has shown liver growth and the expression of hepatocyte markers. This scaffold may be considered for delivery of transdifferentiated hMSCs and maintenance of cell differentiation. ${ }^{98}$

\section{Ocular regeneration}

The use of nanotechnology in ophthalmology is another rapidly growing area of interest. Zarbin et al have provided an excellent review on advancements in regenerative nanomedicine for vision restoration. ${ }^{99}$ In a recent study, Teo et $\mathrm{al}^{100}$ have explored the relationship between the substratum topography and the regeneration of bovine corneal endothelium. They observed that the nano pillars provide better support than the micro wells/pillars and enhance corneal endothelial regeneration by increasing the $\mathrm{Na}^{+} / \mathrm{K}^{+}$ATPase activity and upregulating messenger ribonucleic acid. ${ }^{100}$ In another study, superparamagnetic nanoparticles with tropomyosin-related kinase $\mathrm{B}$ agonist antibodies have been used to activate the tropomyosin-related kinase B-dependent signaling pathway which, in turn, promotes neurite growth. These findings hold potential for using functionalized superparamagnetic nanoparticles to treat injury in the CNS. ${ }^{101}$

Keratocyte development and stromal regeneration are instrumental for vision restoration in diseases such as corneal dystrophy and keratoconus. Uzunalli et $\mathrm{a}^{102}$ have formulated bioactive self-assembled nanofibers from both laminin and fibronectin and compared them for corneal stromal regeneration. The in vitro culture of human keratocytes on these nanofibers has shown significantly improved morphological characteristics and growth in laminin nanofibers. The in vivo studies on damaged rabbit cornea also indicated that laminin mimetic nanofibers augmented keratocytes migration and stromal regeneration. ${ }^{102}$

\section{Pharmacokinetics and toxicology of nanoparticles}

The in vivo behavior of the nanoparticles is the most important factor for examining their toxicity and establishing their efficacy in the biological system. Locally administered nanoparticles usually remain in their local environment for a long period of time and, hence, produce therapeutic effect without causing any toxicity. ${ }^{103}$ In contrast to the locally implanted nanomaterials that have restricted biodistribution, systemically administered nanoparticles have varying pharmacokinetic properties. Biodistribution and pharmacokinetics of nanoparticles are dependent on multiple interrelated physicochemical and biological factors. Some key factors that determine the pharmacokinetic properties 
are: size; morphology; surface characteristics; geometry; and plasma-protein coating. ${ }^{104}$ Similar to other drugs, the nanoparticles' pharmacological activity is evaluated in terms of: 1) absorption; 2) distribution; 3) metabolism; and 4) excretion. An excellent review on the absorption, distribution, metabolism, and excretion properties of nanoparticles is given by $\mathrm{Li}$ et al. ${ }^{105}$

An increase in the capillary permeability of tissues, such as bone marrow, spleen, liver, and tumors, leads to a significant uptake of nanoparticles. The increased rate of nanoparticles uptake by the tumors is called the "enhanced permeability and retention" effect. ${ }^{106}$ Opsonization is a well-known mechanism for the clearance of microbial organisms. Recently, it has been observed that nanoparticles also undergo opsonization and, therefore, get rapidly eliminated from the body. It is evidenced that neutrally charged particles have a much lower opsonization rate than charged particles. ${ }^{107}$ Coating with chemicals is reported to alter the biodistribution and pharmacokinetic profile of nanoparticles. A recent study has shown increased half-life and decreased accumulation of magnetite nanoparticles in the reticuloendothelial system, when coated with PEG. ${ }^{108}$ A study in the mice model has shown that cerium oxide nanoparticles have better bioavailability when administered by the intravenous and intraperitoneal route compared with the oral route. Maximum accumulation of these nanoparticles was found in spleen, followed by the liver, lungs, and kidney. The major route of elimination was via feces, and also no organ toxicities were observed. ${ }^{109}$

The use of nanomaterial in diagnostics and therapy has become important in recent years. It is well-agreed that more definitive research is required to investigate its toxic and potential side effects in the biological system. In fact, this apprehension has led to a dramatic increase in focused safety research. A large number of in vitro studies testing nanomaterial for potential toxicity using cell culture under controlled conditions have been conducted. The basic aim in nanotoxicology is to identify particle physicochemical properties, which are likely to have toxic effects on the biological system. Patel et $\mathrm{al}^{110}$ have well-demonstrated this concept by conducting exposure escalation experiments. This first line of screening method for potentially adverse outcomes consists of exposing the microorganisms or cell lines to a library of nanomaterials. ${ }^{110}$ There is now a need for prioritizing in vivo studies for validating the process. Differential stripping, penetration kinetics of nanoparticles in the stratum corneum, and the evaluation of hair follicles are the three methods available for the assessment of the penetration ability of nanoparticles through the skin barrier into the living tissue. ${ }^{111}$ The exposure escalation experiments are being regularly used to screen the biological safety of nanomaterials in a controlled environment. The experiment explains about the physicochemical properties of the nanoparticles. ${ }^{110}$

Nanoparticles are being increasingly used in drug delivery systems, commercial food products, clothing, and cosmetics. Martirosyan and Schneider have reviewed the consumer safety of nanoparticles used by the general public. ${ }^{112}$ Owing to limited knowledge and restricted studies on the harmful effects of these nanoparticles, exposure risks to patients, health care personnel, research scientists, and the general public remain a matter of concern. More rigorous and controlled studies are necessary to confirm the safety of nanoparticles.

\section{Conclusion and future directions}

The need to apply nanotechnology in regenerative medicine is being increasingly recognized. Incorporation of nanotechnology allows better control over physical and biological properties of a biomaterial than conventional technologies. One of the major applications in this field is the use of nanostructures having native tissue mimicking ability, which has resulted in the development of long-lasting and betterperforming scaffolds. Extensive research is being conducted on the use of scaffolds seeded with stem cells to generate bone and cartilage. However, the success of this technique is limited by the availability of stem cells and their efficiency in regeneration. The enhancement of axonal growth using nanofiber conduits for the treatment of neuronal injuries is also being explored. Efforts are presently directed toward the development of nanofibers, which help provide properties similar to those of natural cardiac tissue. The clinical use of growth factors in wound healing has generated considerable research interest in recent years. Biodegradable scaffolds integrated with multiple growth factors appear to be the most promising therapeutic option for skin tissue regeneration. There is limited work on the application of regenerative nanomedicine in ophthalmology. Nevertheless, efforts are on to explore nano-ophthalmology with an ultimate aim to maintain and restore vision.

Nanotechnology applications to regenerative medicine have all the potential to revolutionize tissue regeneration and repair. However, the development of ideal nanomaterials capable of sending signals to the diseased or damaged cells and tissues to trigger the regeneration process still remains a challenge. It is also difficult to engineer ECM proteins that can function exactly like the native tissue ECM protein in the internal milieu. The careful and radical selection of the new polymer matrix/nanomaterial combination is essential in making scaffolds with superior biomimicking ability, whose 
chemical composition and structure can be well-optimized. Improvement in already existing scaffolds is necessary to overcome the associated limitations. The safety of human health in terms of the use of nanomaterials in regenerative medicine is a matter of considerable concern, because this field is still in its nascent stage. Prior to human applications, studies on the toxic effect of these nanomaterials should be carried out in great detail. Finally, to understand the underlying mechanisms of cell-biomaterial interactions at the nanoscale level, and to be able to translate the findings from bench to bedside, close collaboration between the scientists and clinicians is of utmost importance.

\section{Author contributions}

All authors contributed toward data analysis, drafting and revising the paper and agree to be accountable for all aspects of the work.

\section{Disclosure}

The authors report no conflict of interest in this work.

\section{References}

1. Medical Research Council Centre for Regenerative Medicine. [homepage on the Internet]. What is regenerative medicine? Edinburgh, Scotland: The University of Edinburgh; 2012. Available at: http://www.crm. ed.ac.uk/about/what-regenerative-medicine. Accessed November 29, 2013.

2. Chiapasco M, Giammattei M, Carmagnola D, Autelitano L, Rabbiosi D, Dellavia C. [Iliac crest fresh-frozen allografts and autografts in maxillary and mandibular reconstruction: a histologic and histomorphometric evaluation.] Minerva Stomatol. 2013;62(1-2):3-16. Italian [with English abstract].

3. DePalma AF, Rothman RH, Lewinnek GE, Canale ST. Anterior interbody fusion for severe cervical disc degeneration. Surg Gynecol Obstet. 1972;134(5):755-758.

4. Navarro M, Michiardi A, Castaño O, Planell JA. Biomaterials in orthopaedics. J R Soc Interface. 2008;5(27):1137-1158.

5. Giannoudis PV, Dinopoulos H, Tsiridis E. Bone substitutes: an update. Injury. 2005;36 Supp1 3:S20-S27.

6. Lee JH, Nam H, Ryu HS, Seo JH, Chang BS, Lee CK. Bioactive ceramic coating of cancellous screws improves the osseointegration in the cancellous bone. J Orthop Sci. 2011;16(3):291-297.

7. Zhang L, Webster TJ. Nanotechnology and nanomaterials: promises for improved tissue regeneration. Nano Today. 2009;4(1):66-80.

8. Holmes B, Castro NJ, Li J, Keidar M, Zhang LG. Enhanced human bone marrow mesenchymal stem cell functions in novel 3D cartilage scaffolds with hydrogen treated multi-walled carbon nanotubes. Nanotechnology. 2013;24(36):365102.

9. Peng H, Yin Z, Liu H, et al. Electrospun biomimetic scaffold of hydroxyapatite/chitosan supports enhanced osteogenic differentiation of mMSCs. Nanotechnology. 2012;23(48):485102.

10. Yao C, Slamovich EB, Webster TJ. Enhanced osteoblast functions on anodized titanium with nanotube-like structures. J Biomed Mater Res A. 2008;85(1):157-166.
11. Wang M, Castro NJ, Li J, Keidar M, Zhang LG. Greater osteoblast and mesenchymal stem cell adhesion and proliferation on titanium with hydrothermally treated nanocrystalline hydroxyapatite/ magnetically treated carbon nanotubes. $J$ Nanosci Nanotechnol. 2012;12(10):7692-7702.

12. Jang JH, Castano O, Kim HW. Electrospun materials as potential platforms for bone tissue engineering. Adv Drug Deliv Rev. 2009;61(12): 1065-1083.

13. Wang J, Valmikinathan CM, Liu W, Laurencin CT, Yu X. Spiralstructured, nanofibrous, 3D scaffolds for bone tissue engineering. J Biomed Mater Res A. 2010;93(2):753-762.

14. Alves Cardoso D, Jansen JA, Leeuwenburgh SC. Synthesis and application of nanostructured calcium phosphate ceramics for bone regeneration. J Biomed Mater Res B Appl Biomater. 2012;100(8): 2316-2326.

15. Appleford MR, Oh S, Oh N, Ong JL. In vivo study on hydroxyapatite scaffolds with trabecular architecture for bone repair. J Biomed Mater Res A. 2009;89(4):1019-1027.

16. Raimondo T, Puckett S, Webster TJ. Greater osteoblast and endothelial cell adhesion on nanostructured polyethylene and titanium. Int J Nanomedicine. 2010;5:647-652.

17. Yamada M, Ueno T, Tsukimura N, et al. Bone integration capability of nanopolymorphic crystalline hydroxyapatite coated on titanium implants. Int J Nanomedicine. 2012;7:859-873.

18. Wennerberg A, Jimbo R, Allard S, Skarnemark G, Andersson M. In vivo stability of hydroxyapatite nanoparticles coated on titanium implant surfaces. Int J Oral Maxillofac Implants. 2011;26(6):1161-1166.

19. Tripathi A, Saravanan S, Pattnaik S, Moorthi A, Partridge NC, Selvamurugan N. Bio-composite scaffolds containing chitosan/nanohydroxyapatite/nano-copper-zinc for bone tissue engineering. Int J Biol Macromol. 2012;50(1):294-299.

20. Cao L, Duan PG, Wang HR, et al. Degradation and osteogenic potential of a novel poly(lactic acid)/nano-sized $\beta$-tricalcium phosphate scaffold. Int J Nanomedicine. 2012;7:5881-5888.

21. Azami M, Tavakol S, Samadikuchaksaraei A, et al. A Porous Hydroxyapatite/ Gelatin Nanocomposite Scaffold for Bone Tissue Repair: In Vitro and In Vivo Evaluation. J Biomater Sci Polym Ed. 2012;23(18):2353-2368.

22. Tavakol S, Azami M, Khoshzaban A, et al. Effect of laminated hydroxyapatite/gelatin nanocomposite scaffold structure on osteogenesis using unrestricted somatic stem cells in rat. Cell Biol Int. 2013;37(11): $1181-1189$.

23. Uskoković V, Hoover C, Vukomanović M, Uskoković DP, Desai TA. Osteogenic and antimicrobial nanoparticulate calcium phosphate and poly-(D,L-lactide-co-glycolide) powders for the treatment of osteomyelitis. Mater Sci Eng C Mater Biol Appl. 2013;33(6):3362-3373.

24. Gruskin E, Doll BA, Futrell FW, Schmitz JP, Hollinger JO. Demineralized bone matrix in bone repair: history and use. Adv Drug Deliv Rev. 2012;64(12):1063-1077.

25. Tavakol S, Khoshzaban A, Azami M, et al. The effect of carrier type on bone regeneration of demineralized bone matrix in vivo. $J$ Craniofac Surg. 2013;24(6):2135-2140.

26. Lobo AO, Siqueira IA, das Neves MF, Marciano FR, Corat EJ, Corat MA. In vitro and in vivo studies of a novel nanohydroxyapatite/superhydrophilic vertically aligned carbon nanotube nanocomposites. J Mater Sci Mater Med. 2013;24(7):1723-1732.

27. Hirata E, Ménard-Moyon C, Venturelli E, et al. Carbon nanotubes functionalized with fibroblast growth factor accelerate proliferation of bone marrow-derived stromal cells and bone formation. Nanotechnology. 2013;24(43):435101.

28. Im O, Li J, Wang M, Zhang LG, Keidar M. Biomimetic three-dimensional nanocrystalline hydroxyapatite and magnetically synthesized single-walled carbon nanotube chitosan nanocomposite for bone regeneration. Int J Nanomedicine. 2012;7:2087-2099.

29. Ravichandran R, Gandhi S, SundaramurthiD, Sethuraman S, Krishnan UM. Hierarchical mesoporous silica nanofibers as multifunctional scaffolds for bone tissue regeneration. J Biomater Sci Polym Ed. 2013;24(17):1988-2005. 
30. Marchal JA, Picón M, Perán M, et al. Purification and long-term expansion of multipotent endothelial-like cells with potential cardiovascular regeneration. Stem Cells Dev. 2012;21(4):562-574.

31. Hu J, Feng K, Liu X, Ma PX. Chondrogenic and osteogenic differentiations of human bone marrow-derived mesenchymal stem cells on a nanofibrous scaffold with designed pore network. Biomaterials. 2009;30(28):5061-5067.

32. Bhardwaj N, Kundu SC. Chondrogenic differentiation of rat MSCs on porous scaffolds of silk fibroin/chitosan blends. Biomaterials 2012;33(10):2848-2857.

33. Alves da Silva ML, Martins A, Costa-Pinto AR, et al. Chondrogenic differentiation of human bone marrow mesenchymal stem cells in chitosan-based scaffolds using a flow-perfusion bioreactor. J Tissue Eng Regen Med. 2011;5(9):722-732.

34. Spadaccio C, Rainer A, Trombetta M, et al. Poly-L-lactic acid/ hydroxyapatite electrospun nanocomposites induce chondrogenic differentiation of human MSC. Ann Biomed Eng. 2009;37(7):1376-1389.

35. Lock J, Liu H. Nanomaterials enhance osteogenic differentiation of human mesenchymal stem cells similar to a short peptide of BMP-7. Int J Nanomedicine. 2011;6:2769-2777.

36. Namgung S, Baik KY, Park J, Hong S. Controlling the growth and differentiation of human mesenchymal stem cells by the arrangement of individual carbon nanotubes. ACS Nano. 2011;5(9):7383-7390.

37. Brammer KS, Choi C, Frandsen CJ, Oh S, Johnston G, Jin S. Comparative cell behavior on carbon-coated $\mathrm{TiO}_{2}$ nanotube surfaces for osteoblasts vs osteo-progenitor cells. Acta Biomater. 2011;7(6):2697-2703.

38. Liu D, Yi C, Zhang D, Zhang J, Yang M. Inhibition of proliferation and differentiation of mesenchymal stem cells by carboxylated carbon nanotubes. ACS Nano. 2010;4(4):2185-2195.

39. Smith LA, Liu X, Hu J, Ma PX. The enhancement of human embryonic stem cell osteogenic differentiation with nano-fibrous scaffolding. Biomaterials. 2010;31(21):5526-5535.

40. Metcalfe AD, Ferguson MW. Tissue engineering of replacement skin: the crossroads of biomaterials, wound healing, embryonic development, stem cells and regeneration. J R Soc Interface. 2007;4(14):413-437.

41. Huang S, Fu X. Tissue-engineered skin: bottleneck or breakthrough. Int J Burns Trauma. 2011;1(1):1-10.

42. Vracko R. Basal lamina scaffold-anatomy and significance for maintenance of orderly tissue structure. Am J Pathol. 1974;77(2):314-346.

43. Chandrasekaran AR, Venugopal J, Sundarrajan S, Ramakrishna S. Fabrication of a nanofibrous scaffold with improved bioactivity for culture of human dermal fibroblasts for skin regeneration. Biomed Mater. 2011;6(1):015001.

44. Jin G, Prabhakaran MP, Kai D, Ramakrishna S. Controlled release of multiple epidermal induction factors through core-shell nanofibers for skin regeneration. Eur J Pharm Biopharm. 2013;85(3 Pt A):689-698.

45. Değim Z. Use of microparticulate systems to accelerate skin wound healing. J Drug Target. 2008;16(6):437-448.

46. Li H, Song JH, Park JS, Han K. Polyethylene glycol-coated liposomes for oral delivery of recombinant human epidermal growth factor. Int J Pharm. 2003;258(1-2):11-19.

47. Huang M, Berkland C. Controlled release of repifermin from polyelectrolyte complexes stimulates endothelial cell proliferation. J Pharm Sci. 2009;98(1):268-280.

48. Wu J, Zheng Y, Song W, et al. In situ synthesis of silver-nanoparticles/ bacterial cellulose composites for slow-released antimicrobial wound dressing. Carbohydr Polym. 2014;102:762-771.

49. Reckhenrich AK, Hopfner U, Krötz F, et al. Bioactivation of dermal scaffolds with a non-viral copolymer-protected gene vector. Biomaterials. 2011;32(7):1996-2003.

50. Sun L, Li D, Hemraz UD, Fenniri H, Webster TJ. Self-assembled rosette nanotubes and poly(2-hydroxyethyl methacrylate) hydrogels promote skin cell functions. J Biomed Mater Res A. Epub 2013 Nov 1.

51. Sudheesh Kumar PT, Raj NM, Praveen G, Chennazhi KP, Nair SV, Jayakumar R. In vitro and in vivo evaluation of microporous chitosan hydrogel/nanofibrin composite bandage for skin tissue regeneration. Tissue Eng Part A. 2013;19(3-4):380-392.
52. Jaiswal M, Gupta A, Agrawal AK, Jassal M, Dinda AK, Koul V. Bi-layer composite dressing of gelatin nanofibrous mat and poly vinyl alcohol hydrogel for drug delivery and wound healing application: in-vitro and in-vivo studies. J Biomed Nanotechnol. 2013;9(9):1495-1508.

53. Ravichandran R, Venugopal JR, Sundarrajan S, Mukherjee S, Sridhar R, Ramakrishna S. Composite poly-L-lactic acid/poly- $(\alpha, \beta)$-DL-aspartic acid/collagen nanofibrous scaffolds for dermal tissue regeneration. Mater Sci Eng C Mater Biol Appl. 2012;32(6):1443-1451.

54. Levorson EJ, Raman Sreerekha P, Chennazhi KP, Kasper FK, Nair SV, Mikos AG. Fabrication and characterization of multiscale electrospun scaffolds for cartilage regeneration. Biomed Mater. 2013;8(1):14103.

55. Ustun S, Tombuloglu A, Kilinc M, Guler MO, Tekinay AB. Growth and differentiation of prechondrogenic cells on bioactive self-assembled peptide nanofibers. Biomacromolecules. 2013;14(1):17-26.

56. Frith JE, Cameron AR, Menzies DJ, et al. An injectable hydrogel incorporating mesenchymal precursor cells and pentosan polysulphate for intervertebral disc regeneration. Biomaterials. 2013;34(37):9430-9440.

57. Shafiee A, Soleimani M, Chamheidari GA, et al. Electrospun nanofiberbased regeneration of cartilage enhanced by mesenchymal stem cells. J Biomed Mater Res A. 2011;99(3):467-478.

58. Bain JR. Peripheral nerve allografting: review of the literature with relevance to composite tissue transplantation. Transplant Proc. 1998;30(6):2762-2767.

59. Biazar E, Khorasani MT, Montazeri N, et al. Types of neural guides and using nanotechnology for peripheral nerve reconstruction. Int J Nanomedicine. 2010;5:839-852.

60. Cirillo V, Guarino V, Alvarez-Perez MA, Marrese M, Ambrosio L. J Mater Sci Mater Med. Epub 2014 Apr 16.

61. Koh HS, Yong T, Teo WE, et al. In vivo study of novel nanofibrous intra-luminal guidance channels to promote nerve regeneration. J Neural Eng. 2010;7(4):046003.

62. Oh SH, Kim JR, Kwon GB, Namgung U, Song KS, Lee JH. Effect of surface pore structure of nerve guide conduit on peripheral nerve regeneration. Tissue Eng Part C Methods. 2013;19(3): 233-243.

63. Ouyang Y, Huang C, Zhu Y, Fan C, Ke Q. Fabrication of seamless electrospun collagen/PLGA conduits whose walls comprise highly longitudinal aligned nanofibers for nerve regeneration. J Biomed Nanotechnol. 2013;9(6):931-943.

64. Antoniadou EV, Ahmad RK, Jackman RB, Seifalian AM. Next generation brain implant coatings and nerve regeneration via novel conductive nanocomposite development. Conf Proc IEEE Eng Med Biol Soc. 2011;2011:3253-3257.

65. Fabbro A, Sucapane A, Toma FM, et al. Adhesion to carbon nanotube conductive scaffolds forces action-potential appearance in immature rat spinal neurons. PLoS One. 2013;8(8):e73621.

66. Gelain F, Panseri S, Antonini S, et al. Transplantation of nanostructured composite scaffolds results in the regeneration of chronically injured spinal cords. ACS Nano. 2011;5(1):227-236.

67. Xie J, MacEwan MR, Liu W, et al. Nerve guidance conduits based on double-layered scaffolds of electrospun nanofibers for repairing the peripheral nervous system. ACS Appl Mater Interfaces. 2014;6(12):9472-9480.

68. Masaeli E, Wieringa PA, Morshed M, et al. Peptide functionalized polyhydroxyalkanoate nanofibrous scaffolds enhance Schwann cells activity. Nanomedicine. Epub 2014 May 2.

69. Pinzón-Daza ML, Campia I, Kopecka J, Garzón R, Ghigo D, Riganti C. Nanoparticle- and liposome-carried drugs: new strategies for active targeting and drug delivery across blood-brain barrier. Curr Drug Metab. 2013;14(6):625-640.

70. Azadi A, Hamidi M, Rouini MR. Methotrexate-loaded chitosan nanogels as 'Trojan Horses' for drug delivery to brain: preparation and in vitro/ in vivo characterization. Int J Biol Macromol. 2013;62:523-530.

71. Malmo J, Sandvig A, Vårum KM, Strand SP. Nanoparticle mediated P-glycoprotein silencing for improved drug delivery across the blood-brain barrier: a siRNA-chitosan approach. PLoS One. 2013;8(1):e54182. 
72. Batts KP, Ackermann DM, Edwards WD. Postinfarction rupture of the left ventricular free wall: clinicopathologic correlates in 100 consecutive autopsy cases. Hum Pathol. 1990;21(5):530-535.

73. Hayashi T, Miyataka M, Kimura A, et al. Recent decline in hospital mortality among patients with acute myocardial infarction. Circ J. 2005;69(4): $420-426$.

74. Chang MY, Yang YJ, Chang CH, et al. Functionalized nanoparticles provide early cardioprotection after acute myocardial infarction. J Control Release. 2013;170(2):287-294.

75. Ravichandran R, Seitz V, Reddy Venugopal J, et al. Mimicking native extracellular matrix with phytic acid-crosslinked protein nanofibers for cardiac tissue engineering. Macromol Biosci. 2013;13(3):366-375.

76. Ravichandran R, Venugopal JR, Sundarrajan S, Mukherjee S, Ramakrishna S. Poly(Glycerol sebacate)/gelatin core/shell fibrous structure for regeneration of myocardial infarction. Tissue Eng Part A. 2011;17(9-10):1363-1373.

77. Ravichandran R, Venugopal JR, Sundarrajan S, Mukherjee S, Sridhar R, Ramakrishna S. Minimally invasive injectable short nanofibers of poly(glycerol sebacate) for cardiac tissue engineering. Nanotechnology. 2012;23(38):385102.

78. Deyhle H, Bunk O, Müller B. Nanostructure of healthy and cariesaffected human teeth. Nanomedicine. 2011;7(6):694-701.

79. Tomsia AP, Lee JS, Wegst UG, Saiz E. Nanotechnology for dental implants. Int J Oral Maxillofac Implants. 2013;28(6):e535-e546.

80. Kasaj A, Willershausen B, Reichert C, Röhrig B, Smeets R, Schmidt M. Ability of nanocrystalline hydroxyapatite paste to promote human periodontal ligament cell proliferation. J Oral Sci. 2008;50(3): 279-285.

81. Pilloni A, Pompa G, Saccucci M, et al. Analysis of human alveolar osteoblast behavior on a nano-hydroxyapatite substrate: an in vitro study. BMC Oral Health. 2014;14(1):22.

82. Li F, Peng J, Hu R, et al. Effect of nano-hydroxyapatite suspension on cell proliferation and cycle in human periodontal ligament cells. J Nanosci Nanotechnol. 2013;13(7):4560-4564.

83. Besinis A, van Noort R, Martin N. Remineralization potential of fully demineralized dentin infiltrated with silica and hydroxyapatite nanoparticles. Dent Mater. 2014;30(3):249-262.

84. Yang C, Lee JS, Jung UW, Seo YK, Park JK, Choi SH. Periodontal regeneration with nano-hyroxyapatite-coated silk scaffolds in dogs. J Periodontal Implant Sci. 2013;43(6):315-322.

85. Ghazal M, Hedderich J, Kern M. Wear of feldspathic ceramic, nanofilled composite resin and acrylic resin artificial teeth when opposed to different antagonists. Eur J Oral Sci. 2008;116(6):585-592.

86. Polini A, Bai H, Tomsia AP. Dental applications of nanostructured bioactive glass and its composites. Wiley Interdiscip Rev Nanomed Nanobiotechnol. 2013;5(4):399-410.

87. Wang S, Gao X, Gong W, Zhang Z, Chen X, Dong Y. Odontogenic differentiation and dentin formation of dental pulp cells under nanobioactive glass induction. Acta Biomater. 2014;10(6):2792-2803.

88. Mitsiadis TA, Woloszyk A, Jiménez-Rojo L. Nanodentistry: combining nanostructured materials and stem cells for dental tissue regeneration. Nanomedicine (Lond). 2012;7(11):1743-1753.

89. Qu T, Liu X. Nano-Structured Gelatin/Bioactive Glass Hybrid Scaffolds for the Enhancement of Odontogenic Differentiation of Human Dental Pulp Stem Cells. J Mater Chem B Mater Biol Med. 2013;1(37): 4764-4772.

90. Min JH, Kwon HK, Kim BI. The addition of nano-sized hydroxyapatite to a sports drink to inhibit dental erosion: in vitro study using bovine enamel. J Dent. 2011;39(9):629-635.

91. Kim YS, Kwon HK, Kim BI. Effect of nano-carbonate apatite to prevent re-stain after dental bleaching in vitro. J Dent. 2011;39(9):636-642.

92. Chatzistavrou X, Fenno JC, Faulk D, et al. Fabrication and characterization of bioactive and antibacterial composites for dental applications. Acta Biomater. 2014;10(8):3723-3732.

93. Hernández-Sierra JF, Ruiz F, Pena DC, et al. The antimicrobial sensitivity of Streptococcus mutans to nanoparticles of silver, zinc oxide, and gold. Nanomedicine. 2008;4(3):237-240.
94. Giri S, Braumann UD, Giri P, et al. Nanostructured self-assembling peptides as a defined extracellular matrix for long-term functional maintenance of primary hepatocytes in a bioartificial liver modular device. Int J Nanomedicine. 2013;8:1525-1539.

95. Das S, Roy P, Auddy RG, Mukherjee A. Silymarin nanoparticle prevents paracetamol-induced hepatotoxicity. Int J Nanomedicine. 2011;6:1291-1301.

96. Banas A, Teratani T, Yamamoto Y, et al. Rapid hepatic fate specification of adipose-derived stem cells and their therapeutic potential for liver failure. J Gastroenterol Hepatol. 2009;24(1):70-77.

97. Kazemnejad S, Allameh A, Soleimani M, et al. Biochemical and molecular characterization of hepatocyte-like cells derived from human bone marrow mesenchymal stem cells on a novel threedimensional biocompatible nanofibrous scaffold. $J$ Gastroenterol Hepatol. 2009;24(2):278-287.

98. Tai BC, Du C, Gao S, Wan AC, Ying JY. The use of a polyelectrolyte fibrous scaffold to deliver differentiated hMSCs to the liver. Biomaterials. 2010;31(1):48-57.

99. Zarbin MA, Arlow T, Ritch R. Regenerative nanomedicine for vision restoration. Mayo Clin Proc. 2013;88(12):1480-1490.

100. Teo BK, Goh KJ, Ng ZJ, Koo S, Yim EK. Functional reconstruction of corneal endothelium using nanotopography for tissue-engineering applications. Acta Biomater. 2012;8(8):2941-2952.

101. Steketee MB, Moysidis SN, Jin XL, et al. Nanoparticle-mediated signaling endosome localization regulates growth cone motility and neurite growth. Proc Natl Acad Sci U S A. 2011;108(47):19042-19047.

102. Uzunalli G, Soran Z, Erkal TS, et al. Bioactive self-assembled peptide nanofibers for corneal stroma regeneration. Acta Biomater. 2014;10(3):1156-1166.

103. Wong LL, Hirst SM, Pye QN, Reilly CM, Seal S, McGinnis JF. Correction: Catalytic Nanoceria Are Preferentially Retained in the Rat Retina and Are Not Cytotoxic after Intravitreal Injection. PLoS One. 2013;8(3):e58431.

104. Moghimi SM, Hunter AC, Andresen TL. Factors controlling nanoparticle pharmacokinetics: an integrated analysis and perspective. Annu Rev Pharmacol Toxicol. 2012;52:481-503.

105. Li M, Al-Jamal KT, Kostarelos K, Reineke J. Physiologically based pharmacokinetic modeling of nanoparticles. ACS Nano. 2010;4(11): 6303-6317. Available at: http://dx.doi.org/10.1021/nn1018818. Accessed June 11, 2014.

106. Li SD, Huang L. Pharmacokinetics and biodistribution of nanoparticles. Mol Pharm. 2008;5(4):496-504.

107. Owens DE, Peppas NA. Opsonization, biodistribution, and pharmacokinetics of polymeric nanoparticles. Int J Pharm. 2006;307(1): 93-102.

108. Ruiz A, Hernández Y, Cabal C, et al. Biodistribution and pharmacokinetics of uniform magnetite nanoparticles chemically modified with polyethylene glycol. Nanoscale. 2013;5(23):11400-11408.

109. Hirst SM, Karakoti A, Singh S, et al. Bio-distribution and in vivo antioxidant effects of cerium oxide nanoparticles in mice. Environ Toxicol. 2013;28(2):107-118.

110. Patel T, Telesca D, Low-Kam C, et al. Relating Nanoparticle Properties to Biological Outcomes in Exposure Escalation Experiments. Environmetrics. 2014;25(1):57-68.

111. Warheit DB, Borm PJA, Hennes C, Lademann J. Testing strategies to establish the safety of nanomaterials: conclusions of an ECETOC workshop. Inhal Toxicol. 2007;19(8):631-643.

112. Martirosyan A, Schneider YJ. Engineered nanomaterials in food: implications for food safety and consumer health. Int J Environ Res Public Health. 2014;11(6):5720-5750.

113. Cassidy JW, Roberts JN, Smith CA, et al. Osteogenic lineage restriction by osteoprogenitors cultured on nanometric grooved surfaces: the role of focal adhesion maturation. Acta Biomater. 2014;10(2):651-660.

114. Guasti L, Vagaska B, Bulstrode NW, Seifalian AM, Ferretti P. Chondrogenic differentiation of adipose tissue-derived stem cells within nanocaged POSS-PCU scaffolds: a new tool for nanomedicine. Nanomedicine. 2014;10(2):279-289. 
115. Oseni AO, Butler PE, Seifalian AM. The application of POSS nanostructures in cartilage tissue engineering: the chondrocyte response to nanoscale geometry. J Tissue Eng Regen Med. Epub 2013 Apr 10.

116. Ravichandran R, Sridhar R, Venugopal JR, Sundarrajan S, Mukherjee S, Ramakrishna S. Gold nanoparticle loaded hybrid nanofibers for cardiogenic differentiation of stem cells for infarcted myocardium regeneration. Macromol Biosci. 2014;14(4):515-525.
117. Jiang X, Malkovskiy AV, Tian W, et al. Promotion of airway anastomotic microvascular regeneration and alleviation of airway ischemia by deferoxamine nanoparticles. Biomaterials. 2014;35(2):803-813.

118. Ohtani S, Iwamaru A, Deng W, et al. Tumor suppressor $101 \mathrm{~F} 6$ and ascorbate synergistically and selectively inhibit non-small cell lung cancer growth by caspase-independent apoptosis and autophagy. Cancer Res. 2007;67(13):6293-6303.

\section{Publish your work in this journal}

The International Journal of Nanomedicine is an international, peerreviewed journal focusing on the application of nanotechnology in diagnostics, therapeutics, and drug delivery systems throughout the biomedical field. This journal is indexed on PubMed Central, MedLine, CAS, SciSearch $\AA$, Current Contents ${ }^{\circledR} /$ Clinical Medicine,
Journal Citation Reports/Science Edition, EMBase, Scopus and the Elsevier Bibliographic databases. The manuscript management system is completely online and includes a very quick and fair peer-review system, which is all easy to use. Visit http://www.dovepress.com/ testimonials.php to read real quotes from published authors.

Submit your manuscript here: http://www.dovepress.com/international-journal-of-nanomedicine-journal 